\title{
Nurse plants transfer more nitrogen to distantly related species
}

\author{
Alicia Montesinos-Navarro, $1,2,5$ Miguel Verdú, ${ }^{2}$ José Ignacio Querejeta, ${ }^{3}$ And Alfonso Valiente-Banuet ${ }^{1,4}$ \\ ${ }^{1}$ Departamento de Ecología de la Biodiversidad, Instituto de Ecología, Universidad Nacional Autónoma de México, \\ A.P. 70-275, C.P. 04510, México D.F., México \\ ${ }^{2}$ Centro de Investigaciones sobre Desertificación (CIDE, CSIC-UV-GV), Carretera de Moncada-Náquera Km 4.5, \\ 46113, Moncada, Valencia, Spain \\ ${ }^{3}$ Departamento de Conservación de Suelos y Aguas, Centro de Edafología y Biología Aplicada del Segura (CEBAS-CSIC), \\ Campus de Espinardo, PO Box 4195, E-30100, Murcia, Spain \\ ${ }^{4}$ Centro de Ciencias de la Complejidad, Universidad Nacional Autónoma de México, Ciudad Universitaria, \\ 04510, México D.F., México
}

\begin{abstract}
Plant facilitative interactions enhance co-occurrence between distant relatives, partly due to limited overlap in resource requirements. We propose a different mechanism for the coexistence of distant relatives based on positive interactions of nutrient sharing. Nutrients move between plants following source-sink gradients driven by plant traits that allow these gradients to establish. Specifically, nitrogen $(\mathrm{N})$ concentration gradients can arise from variation in leaf $\mathrm{N}$ content across plants species. As many ecologically relevant traits, we hypothesize that leaf $\mathrm{N}$ content is phylogenetically conserved and can result in $\mathrm{N}$ gradients promoting $\mathrm{N}$ transfer among distant relatives. In a Mexican desert community governed by facilitation, we labelled nurse plants (Mimosa luisana) with ${ }^{15} \mathrm{~N}$ and measured its transfer to 14 other species in the community, spanning the range of phylogenetic distances to the nurse plant. Nurses established steeper $\mathrm{N}$ source-sink gradients with distant relatives, increasing ${ }^{15} \mathrm{~N}$ transfer toward these species. Nutrient sharing may provide long-term benefits to facilitated plants and may be an overlooked mechanism maintaining coexistence and increasing the phylogenetic diversity of plant communities.
\end{abstract}

Key words: coexistence; ${ }^{15} \mathrm{~N}$; nitrogen transfer; nutrient sharing; phylogenetic distance; plant-plant interactions.

\section{INTRODUCTION}

Coexistence theory is framed within the competition paradigm and focuses particularly on species whose coexistence has been traditionally explained by mechanisms stabilizing niche differences or equalizing the fitness of competitive species, ultimately preventing competitive exclusion (Chesson 2000, Mayfield and Levine 2010, Godoy et al. 2014). Recently, there have been attempts to include plant facilitative interactions within coexistence theory, including mechanisms such as realized niche expansion and prevention of local extinction (Bruno et al. 2003, Soliveres et al. 2015, Valladares et al. 2015, Bulleri et al. 2016). Plant facilitative interactions are ubiquitous in many ecosystems (Gómez-Aparicio et al. 2004, Callaway 2007, Brooker et al. 2008) and are important drivers structuring plant communities (Brooker 2006). Facilitative interactions take place when one species (i.e., nurse species) benefits another (i.e., facilitated species) without resulting in any damage to the former or even resulting in a mutual benefit for both species (Callaway 2007, Sortibrán et al. 2014). Some facilitative interactions shift to competition during the ontogeny of the facilitated plant (Schöb et al.

Manuscript received 20 January 2017; accepted 30 January 2017. Corresponding Editor: Serita D. Frey.

5E-mail: ali.montesinos@gmail.com
2014), while others persist over time resulting in adult plant coexistence (Valiente-Banuet and Verdú 2008). Persistent facilitative interactions tend to occur between distantly related plant species, therefore shaping the phylogenetic structure of plant communities (ValienteBanuet et al. 2006, Valiente-Banuet and Verdú 2007, 2013). The mechanisms proposed to maintain these positive interactions through time have also been framed within the competition paradigm, suggesting stabilizing niche differences between the species involved (Pausas and Verdú 2010). Distantly related organisms tend to have little resemblance to each other in terms of physiology, life strategies, or functional traits (Blomberg et al. 2003), resulting in niche segregation, which reduces interspecific competition and enhances coexistence (Webb et al. 2002, Pausas and Verdú 2010). However, the phylogenetic pattern of plant facilitative interactions can also be attributed to a different coexistence mechanism not based on competition but on positive interactions. Differences in functional traits that are evolutionarily conserved can also result in functional complementarity between distant relatives. Phylogenetic patterns in plant nutrient contents can thus result in positive interactions of nutrient sharing between distantly related plants.

In N-limited systems, legumes can increase the $\mathrm{N}$ available in soil through their capacity to establish 
symbiotic associations with $\mathrm{N}_{2}$-fixing microorganisms (Dilworth et al. 2008). Many plant species in semiarid systems require the micro-environmental conditions provided by legumes to establish (Barnes and Archer 1996, Flores and Jurado 2003, Liphadzi and Reinhardt 2006, Valiente-Banuet and Verdú 2007), and these facilitative interactions can take place through several mechanisms including stress amelioration, increased habitat heterogeneity, or sharing mutualisms (Callaway 2007, GómezAparicio 2009, Michalet et al. 2011). Legumes in particular can make a considerable contribution to soil fertility by providing up to $270-550 \mathrm{~kg} \mathrm{~N} \cdot \mathrm{ha}^{-1} \cdot \mathrm{yr}^{-1}$ through root exudates or litter deposition (Sanginga et al. 1994; Jayasundara et al. 1997; Dulormne et al. 2003).

Neighboring plants can exchange nutrients through mycorrhizal fungi present in their shared rhizosphere (Hauggaard-Nielsen and Jensen 2005, Van der Heijden and Horton 2009), resulting in fungal-mediated $\mathrm{N}$ transfer along source-sink $\mathrm{N}$ gradients (i.e., from the $\mathrm{N}$-rich plant to the N-limited plant; Bethlenfalvay et al. 1991, Frey and Schüepp 1993). Species-specific traits influencing $\mathrm{N}$ content can result in source-sink $\mathrm{N}$ gradients among coexisting plants, which may promote nutrient sharing between distantly related species if traits influencing $\mathrm{N}$ content are phylogenetically conserved. Leaf $\mathrm{N}$ content is high in clades harboring $\mathrm{N}$-fixing plants when this trait is analyzed across the entire phylogeny of angiosperms (Cornwell et al. 2014), but $\mathrm{N}$ content can also be phylogenetically conserved independently of this (Stock and Verboom 2012, Yang et al. 2015). Although there is still limited evidence to assess whether closely related species have similar $\mathrm{N}$ content, two types of evidence support the idea that the $\mathrm{N}$ content of plant species can be phylogenetically conserved. Firstly, foliar nutrient content has been shown to be evolutionarily conserved within clades (Nakadai et al. 2014, Oguro and Sakai 2014), and secondly, the capacity for symbiotic $\mathrm{N}_{2}$-fixation is now known to be shared by a monophyletic clade in angiosperms (Werner et al. 2014), resulting in similar foliar $\mathrm{N}$ concentrations among closely related species (i.e., high for nodulating species and low for non-nodulating species; Högberg 1997).

In this study, we hypothesize that (1) foliar $\mathrm{N}$ concentration in facilitated plant species will decrease with increasing phylogenetic distance to the nodulating nurse species thus creating steeper $\mathrm{N}$ source-sink gradients and (2) $\mathrm{N}$ transfer from a nurse plant will increase toward its most distantly related facilitated species. We selected 14 coexisting species in a semiarid Mexican plant community that are facilitated by the $\mathrm{N}$-fixing Mimosa luisana encompassing the range of phylogenetic distances to this nurse. We labelled the nurse $M$. luisana with a ${ }^{15} \mathrm{~N}$-enriched tracer and measured the increase in the foliar $\delta^{15} \mathrm{~N}$ values of the facilitated species after $15 \mathrm{~d}$ as a proxy of the $\mathrm{N}$ transferred from the nurse. With this approach, we test whether inter-plant $\mathrm{N}$ transfer is more likely to occur between distantly related species, providing a new mechanism explaining plant persistence among distantly related species.

\section{Methods \\ Study site and species selection}

The study site was located in the Valley of Zapotitlán $\left(18^{\circ} 21^{\prime} \mathrm{N}, 97^{\circ} 28^{\prime} \mathrm{W}\right)$ in the state of Puebla, Mexico. It is a semiarid region with mean annual temperature of $21^{\circ} \mathrm{C}$, rare frosts, and average annual rainfall of $380 \mathrm{~mm}$, most of which falls during the summer months (June-August; García 1973). The vegetation is a xeric shrubland community dominated by the columnar cactus Neobuxbaumia tetetzo, with plant taxa belonging to the families Fabaceae, Malpighiaceae, Verbenaceae, and Asteraceae among others (Valiente-Banuet et al. 2000). Most plant species in this system are unable to recruit in bare ground and require facilitation by the nurse Mimosa luisana to establish (Verdú and Valiente-Banuet 2008). On the contrary, plants of $M$. luisana rarely establish under a conspecific, usually resulting in vegetation patches containing a single $M$. luisana plant. Different types of benefits are provided by $M$. luisana to the facilitated species. The shade of this deciduous spiny shrub, which can reach heights up to $2-3 \mathrm{~m}$ and a maximum diameter of 1.5-3.0 m, can reduce soil water evaporation, thus increasing moisture availability underneath its canopy. Besides amelioration of abiotic stress, there is also evidence of biotic factors driving facilitation in this system (Castillo et al. 2010, Montesinos-Navarro et al. 2012a, 2016). The establishment, recruitment, and growth of some species depends on the phylogenetic diversity of their neighborhood, suggesting that indirect effects among plants and/or their associated microbiota can shape the outcome of plant facilitative interactions (Castillo et al. 2010). Mimosa luisana harbors the greatest richness of arbuscular mycorrhizal fungi (AMF) in this community, and increasing AMF richness in the shared rhizosphere can promote plant facilitative interactions (Montesinos-Navarro et al. 2012a, b). Finally, M. luisana can also benefit facilitated species through $\mathrm{N}$ fixation, which can be especially relevant in N-limited soils. At our study site, the total soil $\mathrm{N}$ content in bare ground (without any vegetation) is $0.14 \% \pm 0.01 \%$ (Sortibrán et al. 2014), which is relatively low considering that soil $\mathrm{N}$ content across biomes ranges from $0.01 \%$ to $3 \%$ globally (Ordoñez et al. 2009). In addition to M. luisana, there are other $\mathrm{N}$-fixing legumes at the study site that can also provide $\mathrm{N}$ to the shared rhizosphere, including Prosopis laevigata and Acacia coulteri. These legumes facilitate other plant species in the community, but $M$. luisana is by far the highest quality nurse plant as it nurses three times more facilitated plants than any of these other legumes; it is also much more abundant (Valiente-Banuet and Verdú 2007). There is evidence that facilitative interactions drive a patchy vegetation distribution of the vegetation in this environment (Valiente-Banuet and Verdú 2007, 
2008, Castillo et al. 2010, Verdú et al. 2010, Verdú and Valiente-Banuet 2011). Within these vegetation patches, recent studies have shown that the nurse plant can transfer $\mathrm{N}$ to different species of facilitated plants through common mycorrhizal networks (Montesinos-Navarro et al. 2016).

To test our hypotheses, we selected 14 facilitated species that cover the range of phylogenetic distances between $M$. luisana and all species in the community (from 0 million years (Myr; i.e., an individual of $M$. luisana growing in close proximity to another M. luisana) to $322 \mathrm{Myr}$ (Bouteloua gracilis). Therefore, our sampling unit (i.e., replicate) was the phylogenetic distance between $M$. luisana and a facilitated species, and thus we focused our effort on selecting as many phylogenetic distances as possible, rather than multiple individuals of the facilitated species studied. Nevertheless, we also show that our approach is robust to the consideration of intra-specific variation in $\mathrm{N}$ transfer by repeating the analyses using previously published data of intra-specific variation for several plant species from the same study system (Montesinos-Navarro et al. 2016) (see details in Statistical analyses and Appendices S1 and S2). We focused on facilitated species having leaves with a relatively fast turnover to ensure a similar tissue age across species since plant $\delta^{15} \mathrm{~N}$ natural abundance depends on tissue age and type (Dawson et al. 2002). This constraint excluded Cactaceae and Agavaceae from the experiment. The selected facilitated species were: M. luisana, Zapoteca formosa, A. coulteri, P. laevigata, Senna wislizenii, Aeschynomene compacta, Dalea carthagenensis, Echinopterys eglandulosa, Cardiospermum halicacabum, Cissus sicyoides, Thompsonella minutiflora, Loeselia caerulea, Viguiera dentata, and B. gracilis. We subsequently selected one individual per facilitated species growing underneath an adult nurse plant (M. luisana). The 14 facilitated plants were distributed in seven different vegetation patches of $2-3 \mathrm{~m}$ in diameter

TABLE 1. ${ }^{15} \mathrm{~N}$-enrichment in individuals of the nurse species Mimosa luisana labeled with ${ }^{15} \mathrm{~N}$-enriched urea.

\begin{tabular}{lcccc}
\hline \hline Patch & $\begin{array}{c}\delta^{15} \mathrm{~N} \\
\text { before } \\
(\%)\end{array}$ & $\begin{array}{c}\mathrm{N}_{\text {tot }} \\
\text { before } \\
(\mu \mathrm{g} / \mathrm{mg})\end{array}$ & $\begin{array}{c}\delta^{15} \mathrm{~N} \\
\text { after } \\
(\% 0)\end{array}$ & $\begin{array}{c}\mathrm{N}_{\text {tot }} \\
\text { after } \\
(\mu \mathrm{g} / \mathrm{mg})\end{array}$ \\
\hline $\mathrm{A}$ & -0.59 & 33.97 & 133.11 & 30.20 \\
$\mathrm{~B}$ & -0.16 & 32.42 & 212.64 & 28.95 \\
$\mathrm{C}$ & -1.31 & 31.60 & 109.09 & 30.23 \\
$\mathrm{D}$ & -0.60 & 28.38 & $1,879.54$ & 25.51 \\
$\mathrm{E}$ & 1.67 & 34.16 & 12.02 & 28.62 \\
$\mathrm{~F}$ & 0.65 & 30.70 & 122.81 & 30.54 \\
$\mathrm{G}$ & 0.70 & 34.88 & 14.47 & 29.07 \\
Average & 0.05 & 32.30 & 354.81 & 29.02 \\
$\quad$ (SE) & $(0.38)$ & $(0.86)$ & $(255)$ & $(0.64)$ \\
\hline
\end{tabular}

Note: The vegetation patch code in which each labeled nurse plant was located, and the foliar $\delta^{15} \mathrm{~N}$ and $\mathrm{N}$ concentration $\left(\mathrm{N}_{\text {tot }}\right)$ measured before and after the application of the ${ }^{15} \mathrm{~N}-$ enriched tracer are shown. located within an area of $250 \times 250 \mathrm{~m}$ (Tables 1 and 2 ). All patches had a single nurse but a different number of facilitated plants were selected (three patches had one of the selected facilitated plants, two patches had two plants, and the other two patches had three and four plants, respectively).

\section{Phylogenetic distances}

The phylogenetic distance matrix among all study plant species was obtained from a community phylogeny generated with the Phylomatic algorithm implemented in Phylocom 4.2 (Webb et al. 2008). This program produced a community phylogeny by matching the family names of our 14 species with those contained in a backbone phylogeny, the R20120829 megatree assembled following the Angiosperm Phylogeny Group III (Stevens 2005). The tree was further resolved and calibrated with age estimates from Wikström et al. (2001) and Zanne et al. (2014) plus all available ages obtained from chronograms and phylogenies published for specific families and genera. We resolved the phylogenetic relationships at the species level of the Fabaceae family based on published phylogenies of Simon et al. (2009). Finally, we dated nodes of the Poaceae and Malpighiaceae families based on Davis et al. (2005) and Magallón et al. (2015). For the undated nodes, we adjusted branch lengths with the help of BEAST (Bayesian Evolutionary Analysis Sampling Trees; Drummond and Rambaut 2007) and the PolytomyResolver script (Kuhn et al. 2011). This branch length adjustment procedure is based on an evolutionary, birth-death model, which has been shown to be more realistic than traditional non-modelbased approaches (Kuhn et al. 2011). In order to account for the uncertainty in node age estimates using evolutionary models, we repeated all analyses with 100 different phylogenies resulting from the application of this model. The phylogenetic distances between $M$. luisana and the facilitated species were obtained using the ape package (Paradis et al. 2004) and we tested for a phylogenetic signal of leaf $\mathrm{N}$ content using Blomberg's $K$ statistic (Blomberg et al. 2003) implemented in the function phylosig within the phytools package in $\mathrm{R}$ version 3.2.2. In order to ensure that our results were robust despite the uncertainty in the estimation of divergence times among taxa, we repeated all analyses using different estimates of the phylogenetic distance between the 14 facilitated species and M. luisana as reported in the database TimeTree (http://www.timetree.org/). This database compiles expert-knowledge at molecular time estimates of divergence among taxa. We obtained similar results in both cases and therefore, only the analyses based on BEAST are presented.

\section{${ }^{15} \mathrm{~N}$ transfer experiment}

All nurse plants in the seven vegetation patches were successfully labelled by foliar immersion in a ${ }^{15} \mathrm{~N}$-enriched 
TABLE 2. The ${ }^{15} \mathrm{~N}$-enrichment of facilitated species.

\begin{tabular}{|c|c|c|c|c|c|c|}
\hline Facilitated species & Family & $\mathrm{P}$ & $\begin{array}{c}\delta^{15} \mathrm{~N} \text { before } \\
(\%)\end{array}$ & $\begin{array}{c}\mathrm{N}_{\text {tot }} \text { before } \\
(\mathrm{mg} / \mathrm{g})\end{array}$ & $\begin{array}{c}\delta^{15} \mathrm{~N} \text { after } \\
(\% 0)\end{array}$ & $\begin{array}{c}\mathrm{N}_{\text {tot }} \text { after } \\
(\mathrm{mg} / \mathrm{g})\end{array}$ \\
\hline Mimosa luisana $(0)$ & Fabaceae & $\mathrm{F}$ & 2.15 & 34.85 & 2.23 & 31.17 \\
\hline Zapoteca formosa (62) & Fabaceae & $\mathrm{C}$ & 2.07 & 33.14 & 3.20 & 30.27 \\
\hline Acacia coulteri $(86)$ & Fabaceae & A & -0.57 & 36.13 & -0.22 & 32.86 \\
\hline Prosopis laevigata (92) & Fabaceae & A & 2.41 & 39.95 & 2.42 & 37.24 \\
\hline Senna wislizenii (122) & Fabaceae & A & 3.69 & 34.02 & 4.08 & 33.85 \\
\hline Aeschynomene compacta (130) & Fabaceae & $\mathrm{B}$ & -0.76 & 28.99 & -0.54 & 24.46 \\
\hline Dalea carthagenensis (132) & Fabaceae & $\mathrm{D}$ & -0.36 & 27.48 & 0.12 & 27.13 \\
\hline Echinopterys eglandulosa (250) & Malpighiaceae & $\mathrm{D}$ & 2.04 & 46.68 & 1.26 & 42.09 \\
\hline Cardiospermum halicacabum (264) & Sapindaceae & $\mathrm{C}$ & 1.06 & 35.15 & 1.97 & 30.75 \\
\hline Cissus sicyoides (277) & Vitaceae & $\mathrm{C}$ & 2.41 & 35.24 & 5.61 & 35.27 \\
\hline Thompsonella minutiflora (291) & Crassulaceae & G & 1.75 & 15.00 & 3.14 & 14.53 \\
\hline Loeselia caerulea (309) & Polemoniaceae & $\mathrm{E}$ & 1.77 & 6.30 & 4.25 & 10.73 \\
\hline Viguiera dentata (309) & Asteraceae & $\mathrm{C}$ & 2.35 & 31.78 & 3.4 & 28.77 \\
\hline Bouteloua gracilis (322) & Poaceae & $\mathrm{B}$ & -1.04 & 10.16 & 1.33 & 10.50 \\
\hline
\end{tabular}

Notes: The vegetation patch code where each facilitated plant was located $(\mathrm{P})$, and the foliar $\delta^{15} \mathrm{~N}$ and $\mathrm{N}$ concentration $\left(\mathrm{N}_{\text {tot }}\right)$ measured before and after the application of the ${ }^{15} \mathrm{~N}$-enriched tracer to its nurse. The mean phylogenetic distance to $M$. luisana (Myr), averaged across 100 phylogenetic trees is provided in parentheses.

urea solution (Putz et al. 2011) prepared by dissolving $4 \mathrm{~g}$ urea $(98 \% 15 \mathrm{~N}$; Cambridge Isotope Laboratories, (Sercon Ltd., Cheshire, UK)) and $8 \mathrm{~mL}$ surfactant in $2 \mathrm{~L}$ water. Eight tubes of this solution ( $10 \mathrm{~mL}$ per tube) were systemically applied to each individual of $M$. luisana by immersing one branch in each tube. Tubes were attached vertically to branches, placed within a press seal plastic bag and sealed with duct tape to reduce evaporation and avoid spillage (Ledgard et al. 1985). Each M. luisana individual had access to $80 \mathrm{~mL}$ of ${ }^{15} \mathrm{~N}$ solution during 2 weeks. After $15 \mathrm{~d}$, labelled branches were cut to remove the bag without spillage. The seven $M$. luisana nurse plants and the 14 individuals of the facilitated species were sampled immediately before and $15 \mathrm{~d}$ after the ${ }^{15} \mathrm{~N}$ labelling of $M$. luisana to calculate $\mathrm{N}$ transfer. Approximately $1 \mathrm{~g}$ of fresh leaves was collected from each plant at each sampling point. Leaves were collected from different branches to represent the average foliar $\mathrm{N}$ concentration in the whole canopy of the plant. In the case of nurses, the leaves sampled were different from those to which the ${ }^{15} \mathrm{~N}$-enriched solution was applied.

\section{Sample preparation and stable isotope analysis}

The leaf material from each target plant was dried at $50^{\circ} \mathrm{C}$ for $3 \mathrm{~d}$ and ground to a fine powder. Afterward, $3 \mathrm{mg}$ of leaf material per plant was weighed and encapsulated into tin capsules $(8 \times 5 \mathrm{~mm}$; Elementar Americas, $\mathrm{Mt}$ Laurel, New Jersey, USA) for $\mathrm{N}$ isotope analysis $\left(\delta^{15} \mathrm{~N}\right)$ and total $\mathrm{N}$ concentration measurements (hereafter $\mathrm{N}_{\text {tot }}$ ). In order to estimate the repeatability of the measurements, $7 \%$ of the sampled were analyzed twice. The $\delta^{15} \mathrm{~N}$ analyses were conducted at the University of California, Davis Stable Isotope Facility (SIF), using a PDZ Europa ANCA-GSL elemental analyzer interfaced to a PDZ
Europa 20-20 continuous flow isotope ratio mass spectrometer (Sercon Ltd., Cheshire, UK). Conventional delta $(\delta)$ notation is used to report the isotope ratios of foliar samples (expressed in parts per thousand, \%o) relative to international standards (atmospheric $\mathrm{N}_{2}$; Coplen 1994). Analytical error for $\delta^{15} \mathrm{~N}$ measurements is $\pm 0.3 \%$.

\section{Calculation of the variables}

To test whether inter-plant $\mathrm{N}$ transfer increases with steeper $\mathrm{N}$ source-sink gradients, we calculated two variables: $\mathrm{N}$ transference and $\mathrm{N}_{\text {tot }}$ gradient. The amount of $\mathrm{N}$ transference (i.e., ${ }^{15} \mathrm{~N}$-tracer transferred from the nurse to each facilitated species) was estimated as the increase in foliar $\delta^{15} \mathrm{~N}$ observed in the facilitated species $15 \mathrm{~d}$ after the ${ }^{15} \mathrm{~N}$ labeling of their nurse $\left(\delta^{15} \mathrm{~N}_{\text {after }}-\delta^{15} \mathrm{~N}_{\text {before }}\right)$. The $\mathrm{N}_{\text {tot }}$ gradient was estimated as the difference in foliar $\mathrm{N}_{\text {tot }}$ between the nurse and each facilitated plant $\left(\right.$ Nurse $_{\mathrm{N}_{\text {tot }}}-$ Facilit $_{\mathrm{N}_{t o}}$ ).

\section{Statistical analyses}

We used three Bayesian generalized linear models (GLM) to test whether (a) foliar $\mathrm{N}_{\text {tot }}$ in facilitated species decreases with their phylogenetic distance to M. luisana, (b) inter-plant $\mathrm{N}$ transfer increases with steeper sourcesink gradients, and (c) the amount of $\mathrm{N}$ transferred to the facilitated species increases with the phylogenetic distance to $M$. luisana. We used as dependent variable Facilit ${ }_{\mathrm{N}_{\text {tot }}}$ in model a, and the amount of $\mathrm{N}$ transference in the models $\mathrm{b}$ and $\mathrm{c}$; and as fixed explanatory variables, the phylogenetic distance to $M$. luisana in models a and $\mathrm{c}$, and $\mathrm{N}_{\text {tot }}$ gradient in model $\mathrm{b}$. The Bayesian approach allows the incorporation of the variance in the node ages estimated by BEAST. To do so, we ran a GLM model for each of 
the 100 randomly selected phylogenies generated by BEAST. Then we drew 1000 random samples of the Markov chains iterations across these 100 models to obtain an approximation to the posterior distribution of the estimate (i.e., the slope of the relationship between the dependent and the explanatory variable). We ran the three models using physical distance to the nurse and nurse enrichment in ${ }^{15} \mathrm{~N}$ as random factors. This indirectly accounts for the spatial distribution of facilitated species in the seven patches as facilitated individuals sharing a vegetation patch also share a nurse (with a specific $15 \mathrm{~N}$-enrichment). We used the default priors with 250,000 MCMC (Markov chain Monte Carlo) iterations sampled every 100 and discarded a burn-in period of 50,000. We performed additional analyses to account for intraspecific variation in the amount of ${ }^{15} \mathrm{~N}$ transferred to the facilitated plants. These analyses were based on published data from a parallel experiment conducted in the same system (Montesinos-Navarro et al. 2016), where intraspecific variation could be calculated for a subset of the facilitated species. These analyses, which accounted for intraspecific variation, yielded similar results to those considering one individual per species. Thus, we only report and discuss the latter in the main text with further details about the former provided in Appendices S1 and S2.

In all cases convergence was assessed by visual inspection and the settings were chosen to maintain the autocorrelation between successive stored iterations below 0.1 (Hadfield 2010). For each of the three tests we drew a histogram showing the posterior distribution of the estimates of the slope. In addition, we used the posterior distribution of the estimates of the slope to provide the probability that the estimate is higher or lower than zero depending on the expectations for each specific test, and we drew a histogram with the estimates in order to facilitate the assessment of which proportion resulted in a positive slope (greater than 0). All the analyses were performed using the MCMCglmm package (Hadfield 2010) for R software version 3.2.2.

\section{RESUlts}

The amount of ${ }^{15} \mathrm{~N}$ tracer transferred from the nurse plant to the facilitated species was not significantly correlated with competitive effects driven by either the total number of species $(N=14, \mathrm{df}=12, t=1.49, P$ value $=0.16)$, the total number of individuals $(N=14$, df $=12, t=0.66$, $P$ value $=0.52)$ or the number of selected plants growing in its patch $(N=14, \mathrm{df}=12, t=0.21, P$ value $=0.84)$, so these variables were not included in further analyses. Both the physical distance to the nurse and nurse enrichment in ${ }^{15} \mathrm{~N}$ were accounted for in the analyses including them as random factors. We found that foliar $\mathrm{N}_{\text {tot }}$ of facilitated species was phylogenetically conserved ( $K$-statistic significantly higher than $0: K=1.17 P$ value $<0.05)$ and decreased with phylogenetic distance to the nurse $M$. luisana (posterior mean estimate of the slope $=-0.050$; Probability of the slope being lower than $0=95.6 \%$, Fig. 1), thus generating steeper $\mathrm{N}_{\text {tot }}$ gradients in distantly related facilitated plants. At the beginning of the experiment, the average (mean $\pm \mathrm{SE}$ ) foliar $\mathrm{N}_{\text {tot }}$ concentration in the $M$. luisana plants $\left(\right.$ Nurse $_{\mathrm{N}_{\text {tot }}}$ ) was $32.11 \pm 0.54 \mathrm{mg} / \mathrm{g}$, whereas foliar

\section{Posterior distributions of the slopes estimates}
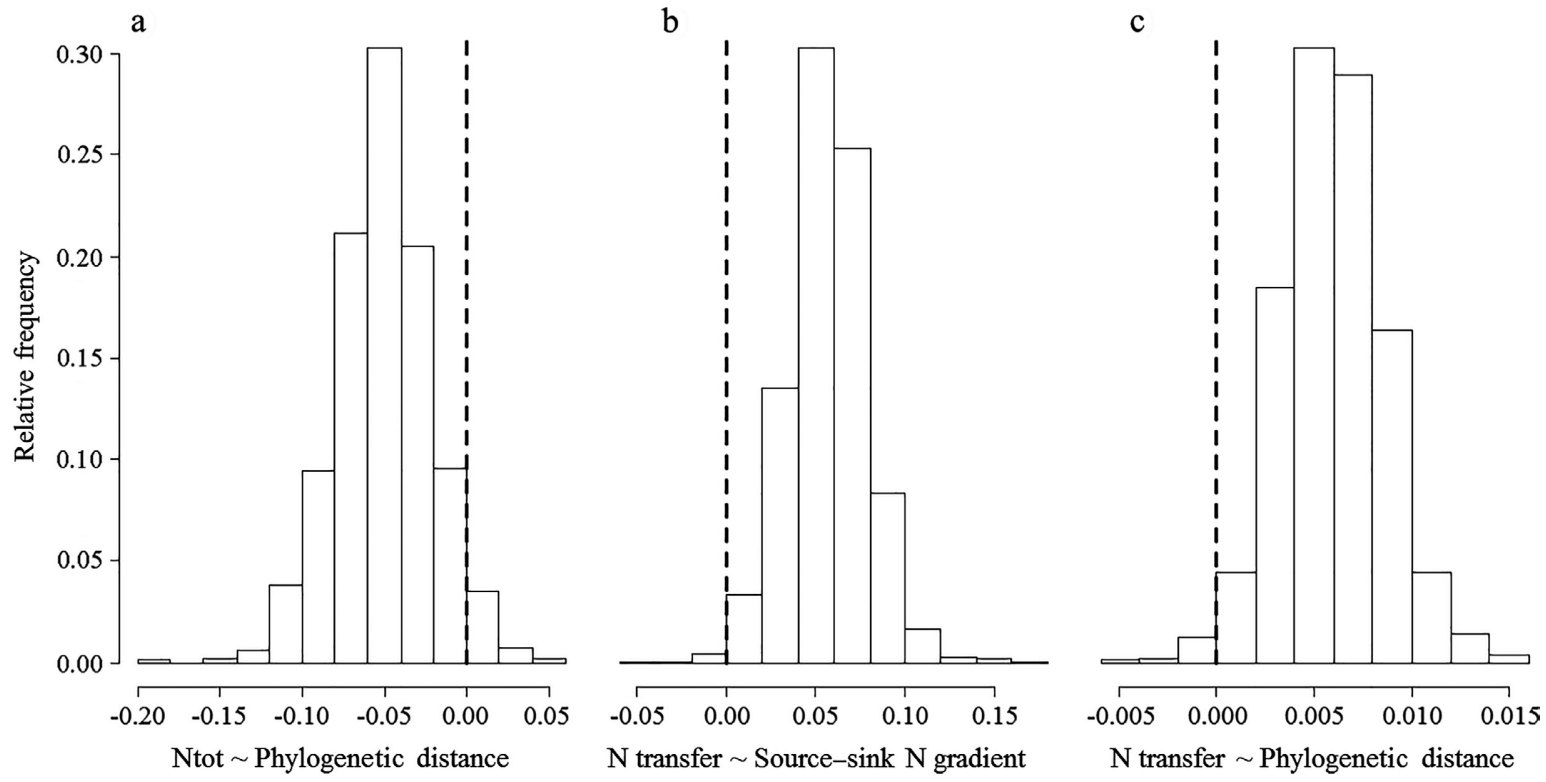

FIG. 1. The posterior distribution of the estimates of the slopes for each of the three hypothesis tested: (a) a negative slope between the foliar $\mathrm{N}$ concentration $\left(\mathrm{N}_{\text {tot }}\right)$ and the phylogenetic distance to Mimosa luisana, (b) a positive slope between $\mathrm{N}$ transfer $\left(\delta^{15} \mathrm{~N}_{\text {After }}-\delta^{15} \mathrm{~N}_{\text {Before }}\right)$ and $\mathrm{N}$ source-sink gradients (Nurse $\mathrm{N}_{t o t}-$ Facilit $\left._{\mathrm{N}_{t o t}}\right)$, and (c) a positive slope between $\mathrm{N}$ transfer and the phylogenetic distance to the nurse. 


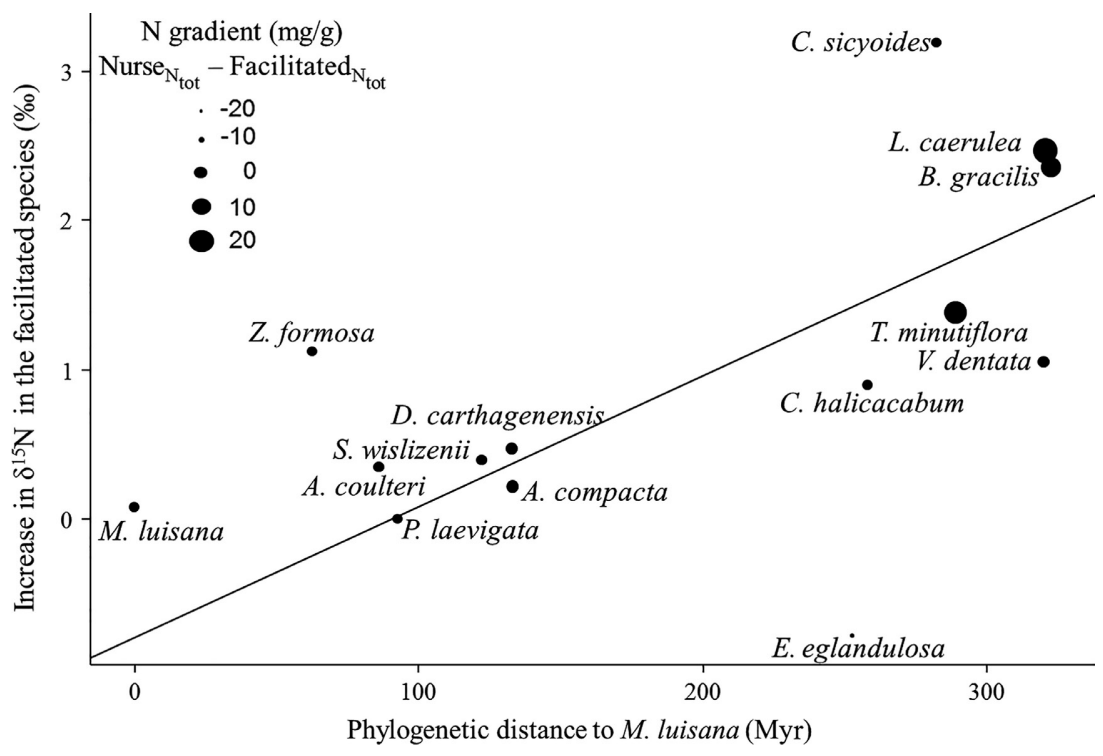

FIG. 2. Increase in ${ }^{15} \mathrm{~N}$ transfer from the nurse to distantly related facilitated species following a source-sink gradient. For each facilitated species, the nitrogen transfer from the nurse is estimated as the increase in foliar $\delta^{15} \mathrm{~N}$ values $(\%) 15 \mathrm{~d}$ after the ${ }^{15} \mathrm{~N}$ labeling of their nurse $\left(\delta^{15} \mathrm{~N}_{\text {After }}-\delta^{15} \mathrm{~N}_{\text {Before }}\right)$. The size of each point represents the $\mathrm{N}_{\text {tot }}$ concentration (mg/g) gradient between the nurse and the facilitated plant (foliar $\mathrm{N}$ concentration of the nurse - foliar $\mathrm{N}$ concentration of the facilitated) at the beginning of the experiment. Phylogenetic distance is expressed in millions of years (Myr). Species names are spelled out in Table 2.

$\mathrm{N}_{\text {tot }}$ concentration in the 14 facilitated species (Facilit ${ }_{\mathrm{N}_{\text {tot }}}$ ) ranged from $6.29 \mathrm{mg} / \mathrm{g}$ (Loeselia caerulea) to $46.68 \mathrm{mg} / \mathrm{g}$ (Echinopterys eglandulosa). On average, the $\mathrm{N}_{\text {tot }}$ gradient between each nurse and its facilitated plant species Nurse $_{\mathrm{N}_{\text {tot }}}-$ Facilit $_{\mathrm{N}_{\text {tot }}}$ ) was $3.48 \pm 3.32 \mathrm{mg} / \mathrm{g}$.

The seven nurse plants successfully enriched with ${ }^{15} \mathrm{~N}$ showed a mean enrichment $\left(\delta^{15} \mathrm{~N}_{\text {After }}-\delta^{15} \mathrm{~N}_{\text {Before }}\right)$ of $355 \pm 256 \%$ o (Table 1). Thirteen out of the 14 facilitated species also showed an increase in their foliar $\delta^{15} \mathrm{~N}$ values after $15 \mathrm{~d}$ of the labeling of their nurse $($ mean $=1.08 \pm 0.28 \%$; Table 2$)$, meanwhile E. eglandulosa, showed slightly lower $\delta^{15} \mathrm{~N}$ values (change in $\left.\delta^{15} \mathrm{~N}=-0.78 \% 0\right)$.

We found that ${ }^{15} \mathrm{~N}$ transfer from the nurse to the facilitated plants increased with the phylogenetic distance between them (Fig. 2; posterior mean estimate of the slope $=0.006$; probability of the slope being greater than $0=98.5 \%$, Fig. 1). ${ }^{15} \mathrm{~N}$ transfer followed a source-sink gradient, with increasing ${ }^{15} \mathrm{~N}$ transfer toward those facilitated species generating steeper $\mathrm{N}_{\text {tot }}$ gradients (posterior mean estimate of the slope $=0.056$; probability of the slope being greater than $0=99.3 \%$, Fig. 1).

\section{Discussion}

Classical explanations for the maintenance of facilitative interactions between distantly related species have suggested the avoidance of competitive exclusion through niche segregation (Webb et al. 2002, Pausas and Verdú 2010). We show that a phylogenetic signal in the sourcesink $\mathrm{N}$ gradients among coexisting plant species correlates with an enhancement of inter-plant $\mathrm{N}$ transfer between distantly related species. This phylogenetic pattern in the positive interactions of nutrient sharing provides a new, non-exclusive, functional mechanism that may also contribute to explain coexistence of distantly related plants (Valiente-Banuet et al. 2006, ValienteBanuet and Verdú 2007, 2013, Castillo et al. 2010).

Facilitative interactions initially allow plant coexistence by providing suitable regeneration niches for distantly related plant species, ultimately increasing the phylogenetic diversity of plant communities (ValienteBanuet and Verdú 2007). Plant phylogenetic diversity increased by plant facilitation enhances soil microbial productivity and ecosystem functioning (Navarro-Cano et al. 2014). Our results shed light on a novel mechanism potentially enhancing facilitative interactions across distantly related species.

We found evidence of a statistically significant enhancement of inter-plant $\mathrm{N}$ transfer between distantly related species. Echinopterys eglandulosa showed no evidence of $\mathrm{N}$ transfer despite its large phylogenetic distance to the nurse $M$. luisana. However, this species had the highest foliar $\mathrm{N}_{\text {tot }}$ concentration of the sampled species, even higher than its nurse plant. Several processes can result in unexpected patterns like this. Echinopterys eglandulosa was associated with a nurse plant with relatively low foliar $\mathrm{N}$ concentration compared to other plants of M. luisana sampled (Patch D, Table 1). N-poor $M$. luisana individuals might tend to retain $\mathrm{N}$ instead of transferring it to other species, which would explain why this nurse plant, despite its high $\delta^{15} \mathrm{~N}$ enrichment, did not transfer much ${ }^{15} \mathrm{~N}$ to its facilitated plants. This tendency might also explain the wide differences in the $\delta^{15} \mathrm{~N}$ 
enrichment among nurse plants, which did not show a clear correlation with the amount of ${ }^{15} \mathrm{~N}$ transferred to their facilitated plants. However, despite the above mentioned ecological effects, there is evidence that foliar $\mathrm{N}$ concentration is evolutionarily conserved (Nakadai et al. 2014, Oguro and Sakai 2014, Werner et al. 2014), so that these exceptions to the general rule are unlikely to affect the generality of the reported phylogenetically conserved source-sink $\mathrm{N}$ gradient among species.

The increases in foliar $\delta^{15} \mathrm{~N}$ values found in facilitated plants after $15 \mathrm{~d}$ were relatively small $(1.08 \%$ o $\pm 0.28 \%$ ). However, it must be considered that firstly, the magnitude is high enough that it is unlikely to be driven by natural temporal variation in foliar $\delta^{15} \mathrm{~N}$ (Garten 1993), and secondly, that $\mathrm{N}$ transfer can be accumulated over time. On one hand, when ${ }^{15} \mathrm{~N}$ transfer is relatively small, natural temporal fluctuations in foliar $\delta^{15} \mathrm{~N}$ values might blur the isotopic signal resultant from the transfer of the ${ }^{15} \mathrm{~N}$-enriched tracer. Thus, in order to minimize natural $\delta^{15} \mathrm{~N}$ variation in the focal facilitated species, we allowed a relatively short period of time for ${ }^{15} \mathrm{~N}$ transfer to occur (15d). The mean standard error of foliar $\delta^{15} \mathrm{~N}$ for the five species for which we could estimate intra-specific variation across individuals was 0.8 , and the intra-individual temporal variation has been shown to be even smaller (Appendix S2). The magnitude of intra-individual fluctuations in foliar $\delta^{15} \mathrm{~N}$ for deciduous trees between spring and fall has been shown to be $<0.3 \%$ (Garten 1993), and similar temporal fluctuations have also been reported for root $\delta^{15} \mathrm{~N}$ values (Sierra et al. 2007). Thus, considering that the increases in leaf $\delta^{15} \mathrm{~N}$ values reported here are above $0.3 \%$ o for 7 of the 14 species, natural temporal variations of foliar $\delta^{15} \mathrm{~N}$ values are not likely to strongly affect the pattern shown here. On the other hand, the relatively short period of time allowed for ${ }^{15} \mathrm{~N}$ transfer to occur might have reduced the recovery of ${ }^{15} \mathrm{~N}$ in the facilitated species. However there is evidence that interplant $\mathrm{N}$ transfer can increase considerably when measured over longer periods (Sierra et al. 2007, Jalonen et al. 2009a, b). Taking this into consideration, the modest increase in leaf $\delta^{15} \mathrm{~N}$ values reported here might be ecologically relevant in the long term considering that $\mathrm{N}$-transfer estimates can reach up to $30-40 \%$ of the total $\mathrm{N}$ in the receiver plants when measured over several months (Høgh-Jensen and Schjoerring 1997, Rasmussen et al. 2007). Finally, we consider it unlikely that the observed pattern is driven by interspecific differences in the natural rates of leaf ${ }^{15} \mathrm{~N}$ accumulation. We showed previously in a simultaneous experiment similarly measuring ${ }^{15} \mathrm{~N}$ transfer from nurse plants to their facilitated species (Montesinos-Navarro et al. 2016), that leaf $\delta^{15} \mathrm{~N}$ enrichment across facilitated plant species was significantly reduced when soil fungal abundance was reduced using a fungicide. This implies that the leaf $\delta^{15} \mathrm{~N}$ enrichment observed in facilitated plants was due to actual ${ }^{15} \mathrm{~N}$ tracer transfer from the nurse plants, and not driven by interspecific differences in the rates of natural $15 \mathrm{~N}$ accumulation.
Two strands of knowledge together suggest that interplant nutrient transfer can be a widespread mechanism enhancing facilitation between distantly related plant species: (1) the ubiquity of nodulating legume species as high quality nurses and (2) a phylogenetically structured $\mathrm{N}$ source-sink gradient across the angiosperms. Firstly, $\mathrm{N}$-fixing species, like legumes, are crucial for the establishment of many species in semiarid environments due to their ability to modify the nutritional, physical and chemical properties of the soil, thus diminishing abiotic stress for other species (Barnes and Archer 1996, Flores and Jurado 2003, Liphadzi and Reinhardt 2006, Navarro-Cano et al. 2014). Secondly, only the closely phylogenetically related nodulating plant species have the ability to use an extra source of $\mathrm{N}$ (i.e., atmospheric $\mathrm{N}_{2}$ ) through symbiosis with $\mathrm{N}_{2}$-fixing rhizobacteria (Werner et al. 2014), which enables the emergence of phylogenetically structured N source-sink gradients in multiple ecosystems. Finally, inter-plant transfers along source-sink gradients have also been reported for other nutrients such as phosphorus and carbon (Bethlenfalvay et al. 1991, Frey and Schüepp 1992, Simard et al. 1997, 2012) and resources such as water (Egerton-Warburton et al. 2007, Querejeta et al. 2012), thus raising the possibility that the phylogenetically driven mechanism reported here could also be at play for inter-plant transfers of these other limiting resources. However, most of the current knowledge about $\mathrm{N}$ transfer has been generated in agro-ecosystems and based on a legume as a donor (Chalk 1996, He et al. 2009, Chalk et al. 2014). Further research is required to assess the ecological implications of $\mathrm{N}$ transfer in facilitative interactions when nonlegumes are the main nurse species in the community.

From an evolutionary perspective, an immediate question arising from our results is how $\mathrm{N}$ transfer from $\mathrm{N}$-rich plants to their neighbors can be evolutionary stable. We propose different reasons below deserving further research. First, trade-offs between the ability to capture nutrients and store them can result in a poor capacity of N-rich plants to retain N. Some traits allow a more rapid acquisition of resources from the rhizosphere, such as total root length (Craine et al. 2005, Olde Venterink 2011), while others prevent nutrient losses and favor storage, such as long leaf lifespan, defenses against herbivores, and high nutrient-resorption efficiency (Harrington et al. 2001, Treseder and Vitousek 2001, Güsewell 2005a, b, Lambers et al. 2008, 2010, Olde Venterink 2011). Each strategy is favored under different nutrient-limiting environments, so while acquisitive traits are favored in N-limiting environments, storage traits are favored under P limitation (Olde Venterink 2011). This suggests that potential trade-offs between these two strategies might emerge in environments colimited by multiple nutrients. Second, N-rich nurse species could transfer N in exchange for other resources received from their facilitated plant species. Plant species differ in their functional traits, and this can provide different benefits to neighbor plants. For example, grasses have been suggested to be 
sinks (receivers) of $\mathrm{N}$, whereas legumes can act as $\mathrm{P}$ sinks (Johansen and Jensen 1996, Meding and Zasoski 2008), providing the possibility for a mutual interspecific benefit through nutrient exchange. Reciprocal benefits mediated by complementary resource acquisition patterns have been shown for two shrub species intimately interacting in arid environments of southeastern Spain (Tirado et al. 2015). Maytenus senegalensis benefits from the presence of Whitania frutescens by increasing its water potential, while the latter benefits from the former by increasing its leaf $\mathrm{P}$ status (Tirado et al. 2015). Although the specific mechanisms remain largely unexplored, there is evidence of a long-term mutualism between plant species in our study system, suggesting that plant-plant exchange of resources may be involved in this mutualism. Sortibrán et al. (2014) showed that the nurse species M. luisana produced more flowers and fruits when it had facilitated plants growing underneath its canopy than when growing alone. Furthermore, nurse fitness increased with the phylogenetic diversity of the plant neighborhood (Sortibrán et al. 2014), a benefit that disappeared when the mycorrhizal fungal network in the shared rhizosphere was experimentally disrupted (L. Sortibrán, personal communication). Most of the plant species in our system form symbiosis with arbuscular mycorrhizal fungi (CamargoRicalde et al. 2003), which establish common mycorrhizal networks that enhance nutrient transfer between plant species (He et al. 2003, Jalonen et al. 2009b). This supports previous evidence that mycorrhizal fungi play a key role in inter-plant nutrient exchange (He et al. 2009, Chalk et al. 2014), potentially shaping plant facilitation interactions. Whether plant-mycorrhizal relationships can also contribute to the observed phylogenetic pattern in the amount of inter-plant $\mathrm{N}$ transfer is still to be explored.

In conclusion, although more comprehensive measures of plant fitness will be necessary to assess long term community dynamics, we document a phylogenetic signature imprinted by a nutrient sharing mechanism in a natural plant community, providing a novel mechanism that may help to explain coexistence between distantly related species. While the traditional explanations of coexistence have been framed within the competition paradigm, the proposed complementary mechanism is based on positive interactions of nutrients sharing. Our results provide intriguing clues in the search for phylogenetic patterns in the inter-plant transfer of other limiting nutrients, and open new research avenues to deepen current understanding of the coexistence mechanisms that maintain the phylogenetic diversity of plant communities.

\section{AcKnowledgments}

We thank J. P. Castillo and A. Cerón for help with field sampling and Dirk Sanders for insightful comments that improved the clarity of the manuscript. A. Montesinos-Navarro was supported by a postdoctoral contract from the Ministerio de Economía y Competitividad (FPDI-2013-16266; IJCI-201523498; Project CGL2014-58333-P) and an Early Career Project Grant from the British Ecological Society (3975-4849). Funding was also provided by Programa de Apoyo a Proyectos de Investigación e Innovación Tecnológica-Dirección General Asuntos del Personal Académico- Universidad Nacional Autónoma de México PAPIIT-DGAPA-UNAM (IN213414-3). The study has been supported by the TRY initiative on plant traits (http://www.try-db.org). The TRY initiative and database is hosted, developed and maintained by J. Kattge and G. Bönisch (Max Planck Institute for Biogeochemestry, Jena, Germany). TRY is currently supported by DIVERSITAS/ Future Earth and the German Center for Integrative Biodiversity Research (iDiv) Halle-Jena-Leipzig.

\section{Literature Cited}

Barnes, P. W., and S. Archer. 1996. Influence of an overstorey tree (Prosopis glandulosa) on associated shrubs in a savanna parkland: implications for patch dynamics. Oecologia 105:493-500.

Bethlenfalvay, G. J., M. G. Reyes-Solis, S. B. Camel, and R. Ferrera-Cerrato. 1991. Nutrient transfer between the root zones of soybean and maize plants connected by a common mycorrhizal mycelium. Physiologia Plantarum 82: 423-432.

Blomberg, S. P., T. Garland, and A. R. Ives. 2003. Testing for phylogenetic signal in comparative data: behavioral traits are more labile. Evolution 57:717-745.

Brooker, R. W. 2006. Plant-plant interactions and environmental change. New Phytologist 171:271-284.

Brooker, R. W., et al. 2008. Facilitation in plant communities: the past, the present, and the future. Journal of Ecology 96:18-34.

Bruno, J. F., J. J. Stachowicz, and M. D. Bertness. 2003. Inclusion of facilitation into ecological theory. Trends in Ecology \& Evolution 18:119-125.

Bulleri, F., J. F. Bruno, B. R. Silliman, and J. J. Stachowicz. 2016. Facilitation and the niche: implications for coexistence, range shifts and ecosystem functioning. Functional Ecology 30:70-78.

Callaway, R. M. 2007. Positive interactions and interdependence in plant communities. Dordrecht, The Netherlands.

Camargo-Ricalde, S., S. S. Dhillion, and C. Jiménez-González. 2003. Mycorrhizal perennials of the "matorral xerófilo" and the "selva baja caducifolia" communities in the semiarid Tehuacán-Cuicatlán Valley, Mexico. Mycorrhiza 13:77-83.

Castillo, J. P., M. Verdú, and A. Valiente-Banuet. 2010. Neighborhood phylodiversity affects plant performance. Ecology 91:3656-3663.

Chalk, P. M. 1996. Nitrogen transfer from legumes to cereals in intercropping. Pages 351-374 in O. Ito, C. Johansen, J. J. Adu-Gyamfi, K. Katayama, J. V. D. K. Rao, and T. J. Rego, editors. Dynamics of roots and nitrogen in cropping systems of the semiarid tropics. Japan International Research Center for Agricultural Sciences, Ibaraki, Japan.

Chalk, P. M., M. B. Peoples, A. M. McNeill, R. M. Boddey, M. J. Unkovich, M. J. Gardener, C. F. Silva, and D. Chen. 2014. Methodologies for estimating nitrogen transfer between legumes and companion species in agro-ecosystems: a review of $15 \mathrm{~N}$-enriched techniques. Soil Biology and Biochemistry 73:10-21.

Chesson, P. 2000. Mechanisms of maintenance of species diversity. Annual Review of Ecology and Systematics 31:343-366.

Coplen, T. 1994. Reporting of stable hydrogen, carbon, and oxygen isotopic abundances. Pure and Applied Chemistry 66:273-276. 
Cornwell, W. K., et al. 2014. Functional distinctiveness of major plant lineages. Journal of Ecology 102:345-356.

Craine, J. M., J. Fargione, and S. Sugita. 2005. Supply pre-emption, not concentration reduction, is the mechanism of competition for nutrients. New Phytologist 166:933-940.

Davis, C. C., C. O. Webb, K. J. Wurdack, C. A. Jaramillo, and M. J. Donoghue. 2005. Explosive radiation of Malpighiales supports a mid-Cretaceous origin of modern tropical rain forests. American Naturalist 165:E36-E65.

Dawson, T. E., S. Mambelli, A. H. Plamboeck, P. H. Templer, and K. P. Tu. 2002. Stable isotopes in plant ecology. Annual Review of Ecology and Systematics 33:507-559.

Dilworth, M. J., E. K. James, J. I. Sprent, and W. E. Newton. 2008. Nitrogen-fixing leguminous symbioses. Springer, New York, New York, USA.

Drummond, A. J., and A. Rambaut. 2007. BEAST: Bayesian evolutionary analysis by sampling trees. BMC Evolutionary Biology 7:214.

Dulormne, M., J. Sierra, P. Nygren, and P. Cruz. 2003. Nitrogen-fixation dynamics in a cut-and-carry silvopastoral system in the subhumid conditions of Guadeloupe, French Antilles. Agroforestry Systems 59:121-129.

Egerton-Warburton, L. M., J. I. Querejeta, and M. F. Allen. 2007. Common mycorrhizal networks provide a potential pathway for the transfer of hydraulically lifted water between plants. Journal of Experimental Botany 58:1473-1483.

Flores, J., and E. Jurado. 2003. Are nurse-protégé interactions more common among plants from arid environments? Journal of Vegetation Science 14:911-916.

Frey, B., and H. Schüepp. 1992. Transfer of symbiotically fixed nitrogen from berseem (Trifolium alexandrinum L.) to maize via vesicular-arbuscular mycorrhizal hyphae. New Phytologist 122:447-454.

Frey, B., and H. Schüepp. 1993. A role of vesicular-arbuscular (VA) mycorrhizal fungi in facilitating interplant nitrogen transfer. Soil Biology and Biochemistry 25:651-658.

García, E. 1973. Veracruz, modificaciones al sistema de clasificación climática de Koppen. Universidad Nacional Autónoma de México, Instituto de Geografia, Mexico DF, Mexico.

Garten, C. T. 1993. Variation in foliar $15 \mathrm{~N}$ abundance and the availability of soil nitrogen on Walker Branch watershed. Ecology 74:2098-2113.

Godoy, O., N. J. Kraft, and J. M. Levine. 2014. Phylogenetic relatedness and the determinants of competitive outcomes. Ecology Letters 17:836-844.

Gómez-Aparicio, L. 2009. The role of plant interactions in the restoration of degraded ecosystems: a meta-analysis across life-forms and ecosystems. Journal of Ecology 97:1202-1214.

Gómez-Aparicio, L., R. Zamora, J. M. Gómez, J. A. Hódar, J. Castro, and E. Baraza. 2004. Applying plant facilitation to forest restoration: a meta-analysis of the use of shrubs as nurse plants. Ecological Applications 14:1128-1138.

Güsewell, S. 2005a. High nitrogen: phosphorus ratios reduce nutrient retention and second-year growth of wetland sedges. New Phytologist 166:537-550.

Güsewell, S. 2005b. Responses of wetland graminoids to the relative supply of nitrogen and phosphorus. Plant Ecology 176:35-55.

Hadfield, J. D. 2010. MCMC methods for multi-response generalized linear mixed models: the MCMCglmm R package. Journal of Statistical Software 33:1-22.

Harrington, R. A., J. H. Fownes, and P. M. Vitousek. 2001. Production and resource use efficiencies in $\mathrm{N}$-and P-limited tropical forests: a comparison of responses to long-term fertilization. Ecosystems 4:646-657.

Hauggaard-Nielsen, H., and E. S. Jensen. 2005. Facilitative root interactions in intercrops. Plant and Soil 274:237-250.
He, X.-H., C. Critchley, and C. Bledsoe. 2003. Nitrogen transfer within and between plants through common mycorrhizal networks (CMNs). Critical Reviews in Plant Sciences 22: $531-567$.

He, X., M. Xu, G. Y. Qiu, and J. Zhou. 2009. Use of $15 \mathrm{~N}$ stable isotope to quantify nitrogen transfer between mycorrhizal plants. Journal of Plant Ecology 2:107-118.

Høgh-Jensen, H., and J. Schjoerring. 1997. Interactions between white clover and ryegrass under contrasting nitrogen availability: N2 fixation, $\mathrm{N}$ fertilizer recovery, $\mathrm{N}$ transfer and water use efficiency. Plant and Soil 197:187-199.

Högberg, P. 1997. Tansley review no. 95 15N natural abundance in soil-plant systems. New Phytologist 137:179-203.

Jalonen, R., P. Nygren, and J. Sierra. 2009a. Root exudates of a legume tree as a nitrogen source for a tropical fodder grass. Nutrient Cycling in Agroecosystems 85:203-213.

Jalonen, R., P. Nygren, and J. Sierra. 2009b. Transfer of nitrogen from a tropical legume tree to an associated fodder grass via root exudation and common mycelial networks. Plant, Cell \& Environment 32:1366-1376.

Jayasundara, H., M. Dennett, and U. Sangakkara. 1997. Biological nitrogen fixation in Gliricidia sepium and Leucaena leucocephala and transfer of fixed nitrogen to an associated grass. Tropical Grasslands 31:529-537.

Johansen, A., and E. Jensen. 1996. Transfer of N and P from intact or decomposing roots of pea to barley interconnected by an arbuscular mycorrhizal fungus. Soil Biology and Biochemistry 28:73-81.

Kuhn, T. S., A. O. Mooers, and G. H. Thomas. 2011. A simple polytomy resolver for dated phylogenies. Methods in Ecology and Evolution 2:427-436.

Lambers, H., M. C. Brundrett, J. A. Raven, and S. D. Hopper. 2010. Plant mineral nutrition in ancient landscapes: high plant species diversity on infertile soils is linked to functional diversity for nutritional strategies. Plant and Soil 334:11-31.

Lambers, H., J. A. Raven, G. R. Shaver, and S. E. Smith. 2008. Plant nutrient-acquisition strategies change with soil age. Trends in Ecology \& Evolution 23:95-103.

Ledgard, S., J. Freney, and J. Simpson. 1985. Assessing nitrogen transfer from legumes to associated grasses. Soil Biology and Biochemistry 17:575-577.

Liphadzi, K., and C. Reinhardt. 2006. Using companion plants to assist Pinus patula establishment on former agricultural lands. South African Journal of Botany 72:403-408.

Magallón, S., S. Gómez-Acevedo, L. L. Sánchez-Reyes, and T. Hernández-Hernández. 2015. A metacalibrated time-tree documents the early rise of flowering plant phylogenetic diversity. New Phytologist 207:437-453.

Mayfield, M. M., and J. M. Levine. 2010. Opposing effects of competitive exclusion on the phylogenetic structure of communities. Ecology Letters 13:1085-1093.

Meding, S., and R. Zasoski. 2008. Hyphal-mediated transfer of nitrate, arsenic, cesium, rubidium, and strontium between arbuscular mycorrhizal forbs and grasses from a California oak woodland. Soil Biology and Biochemistry 40:126-134.

Michalet, R., S. Xiao, B. Touzard, D. S. Smith, L. A. Cavieres, R. M. Callaway, and T. G. Whitham. 2011. Phenotypic variation in nurse traits and community feedbacks define an alpine community. Ecology Letters 14:433-443.

Montesinos-Navarro, A., J. G. Segarra-Moragues, A. ValienteBanuet, and M. Verdú. 2012a. Plant facilitation occurs between species differing in their associated arbuscular mycorrhizal fungi. New Phytologist 196:835-844.

Montesinos-Navarro, A., J. G. Segarra-Moragues, A. ValienteBanuet, and M. Verdú. 2012b. The network structure of plant-arbuscular mycorrhizal fungi. New Phytologist 194: 536-547. 
Montesinos-Navarro, A., M. Verdú, J. I. Querejeta, L. Sortibrán, and A. Valiente-Banuet. 2016. Soil fungi promote nitrogen transfer among plants involved in long-lasting facilitative interactions. Perspectives in Plant Ecology, Evolution and Systematics 18:45-51.

Nakadai, R., M. Murakami, and T. Hirao. 2014. Effects of phylogeny, leaf traits, and the altitudinal distribution of host plants on herbivore assemblages on congeneric Acer species. Oecologia 175:1237-1245.

Navarro-Cano, J. A., M. Goberna, A. Valiente-Banuet, A. Montesinos-Navarro, C. García, and M. Verdú. 2014. Plant phylodiversity enhances soil microbial productivity in facilitation-driven communities. Oecologia 174: 909-920.

Oguro, M., and S. Sakai. 2014. Difference in defense strategy in flower heads and leaves of Asteraceae: multiple-species approach. Oecologia 174:227-239.

Olde Venterink, H. 2011. Does phosphorus limitation promote species-rich plant communities? Plant and Soil 345:1-9.

Ordoñez, J. C., P. M. Van Bodegom, J.-P. M. Witte, I. J. Wright, P. B. Reich, and R. Aerts. 2009. A global study of relationships between leaf traits, climate and soil measures of nutrient fertility. Global Ecology and Biogeography 18:137-149.

Paradis, E., J. Claude, and K. Strimmer. 2004. APE: analyses of phylogenetics and evolution in R language. Bioinformatics 20:289-290.

Pausas, J. G., and M. Verdú. 2010. The jungle of methods for evaluating phenotypic and phylogenetic structure of communities. BioScience 60:614-625.

Putz, B., T. Drapela, W. Wanek, O. Schmidt, T. Frank, and J. G. Zaller. 2011. A simple method for in situ-labelling with $15 \mathrm{~N}$ and $13 \mathrm{C}$ of grassland plant species by foliar brushing. Methods in Ecology and Evolution 2:326-332.

Querejeta, J. I., L. M. Egerton-Warburton, I. Prieto, R. Vargas, and M. F. Allen. 2012. Changes in soil hyphal abundance and viability can alter the patterns of hydraulic redistribution by plant roots. Plant and Soil 355:63-73.

Rasmussen, J., J. Eriksen, E. S. Jensen, K. H. Esbensen, and H. Høgh-Jensen. 2007. In situ carbon and nitrogen dynamics in ryegrass-clover mixtures: transfers, deposition and leaching. Soil Biology and Biochemistry 39:804-815.

R Core Team. 2013. R: A language and environment for statistical computing. R Foundation for Statistical Computing, Vienna, Austria. http://www.R-project.org/

Sanginga, N., S. Danso, F. Zapata, and G. Bowen. 1994. Influence of pruning management on $\mathrm{P}$ and $\mathrm{N}$ distribution and use efficiency by $\mathrm{N} 2$ fixing and non-N2 fixing trees used in alley cropping systems. Plant and Soil 167:219-226.

Schöb, C., et al. 2014. The context dependence of beneficiary feedback effects on benefactors in plant facilitation. New Phytologist 204:386-396.

Sierra, J., D. Daudin, A.-M. Domenach, P. Nygren, and L. Desfontaines. 2007. Nitrogen transfer from a legume tree to the associated grass estimated by the isotopic signature of tree root exudates: a comparison of the $15 \mathrm{~N}$ leaf feeding and natural $15 \mathrm{~N}$ abundance methods. European Journal of Agronomy 27:178-186.

Simard, S. W., K. J. Beiler, M. A. Bingham, J. R. Deslippe, L. J. Philip, and F. P. Teste. 2012. Mycorrhizal networks: mechanisms, ecology and modelling. Fungal Biology Reviews 26: $39-60$.

Simard, S. W., D. A. Perry, M. D. Jones, D. D. Myrold, D. M. Durall, and R. Molina. 1997. Net transfer of carbon between ectomycorrhizal tree species in the field. Nature 388: 579-582.

Simon, M. F., R. Grether, L. P. de Queiroz, C. Skema, R. T. Pennington, and C. E. Hughes. 2009. Recent assembly of the
Cerrado, a neotropical plant diversity hotspot, by in situ evolution of adaptations to fire. Proceedings of the National Academy of Sciences USA 106:20359-20364.

Soliveres, S., F. T. Maestre, M. Berdugo, and E. Allan. 2015. A missing link between facilitation and plant species coexistence: nurses benefit generally rare species more than common ones. Journal of Ecology 103:1183-1189.

Sortibrán, L., M. Verdú, and A. Valiente-Banuet. 2014. Nurses experience reciprocal fitness benefits from their distantly related facilitated plants. Perspectives in Plant Ecology, Evolution and Systematics 16:228-235.

Stevens, P. 2005. Angiosperm Phylogeny Website. Version 9, June 2008. http://www.mobot.org/MOBOT/research/APweb

Stock, W. D., and G. A. Verboom. 2012. Phylogenetic ecology of foliar $\mathrm{N}$ and $\mathrm{P}$ concentrations and $\mathrm{N}$ : $\mathrm{P}$ ratios across mediterranean-type ecosystems. Global Ecology and Biogeography 21:1147-1156.

Tirado, R., K. A. Bråthen, and F. I. Pugnaire. 2015. Mutual positive effects between shrubs in an arid ecosystem. Scientific Reports 5:14710.

Treseder, K. K., and P. M. Vitousek. 2001. Effects of soil nutrient availability on investment in acquisition of $\mathrm{N}$ and $\mathrm{P}$ in Hawaiian rain forests. Ecology 82:946-954.

Valiente-Banuet, A., A. Casas, A. Alcántara, P. Dávila, N. F. Hernández, M. del Coro Arizmendi, J. L. Villaseñor, and J. O. Ramirez. 2000. La vegetación del valle de TehuacánCuicatlán. Boletin de la Sociedad Botánica de México 67:25-74.

Valiente-Banuet, A., A. V. Rumebe, M. Verdú, and R. M. Callaway. 2006. Modern quaternary plant lineages promote diversity through facilitation of ancient tertiary lineages. Proceedings of the National Academy of Sciences USA 103:16812-16817.

Valiente-Banuet, A., and M. Verdú. 2007. Facilitation can increase the phylogenetic diversity of plant communities. Ecology Letters 10:1029-1036.

Valiente-Banuet, A., and M. Verdú. 2008. Temporal shifts from facilitation to competition occur between closely related taxa. Journal of Ecology 96:489-494.

Valiente-Banuet, A., and M. Verdú. 2013. Plant facilitation and phylogenetics. Annual Review of Ecology, Evolution, and Systematics 44:347-366.

Valladares, F., C. C. Bastias, O. Godoy, E. Granda, and A. Escudero. 2015. Species coexistence in a changing world. Frontiers in Plant Science 6:866.

Van der Heijden, M. G., and T. R. Horton. 2009. Socialism in soil? The importance of mycorrhizal fungal networks for facilitation in natural ecosystems. Journal of Ecology 97:1139-1150.

Verdú, M., P. Jordano, and A. Valiente-Banuet. 2010. The phylogenetic structure of plant facilitation networks changes with competition. Journal of Ecology 98: $1454-1461$.

Verdú, M., and A. Valiente-Banuet. 2008. The nested assembly of plant facilitation networks prevents species extinctions. American Naturalist 172:751-760.

Verdú, M., and A. Valiente-Banuet. 2011. The relative contribution of abundance and phylogeny to the structure of plant facilitation networks. Oikos 120:1351-1356.

Webb, C. O., D. D. Ackerly, and S. W. Kembel. 2008. Phylocom: software for the analysis of phylogenetic community structure and trait evolution. Bioinformatics 24:2098-2100.

Webb, C. O., D. D. Ackerly, M. A. McPeek, and M. J. Donoghue. 2002. Phylogenies and community ecology. Annual Review of Ecology and Systematics 33:475-505.

Werner, G. D., W. K. Cornwell, J. I. Sprent, J. Kattge, and E. T. Kiers. 2014. A single evolutionary innovation drives the 
deep evolution of symbiotic N2-fixation in angiosperms. Nature Communications 5:4087.

Wikström, N., V. Savolainen, and M. W. Chase. 2001. Evolution of the angiosperms: calibrating the family tree. Proceedings of the Royal Society B 268:2211-2220.
Yang, X., et al. 2015. Variations of leaf N, P concentrations in shrubland biomes across northern China: phylogeny, climate and soil. Variations 12:18973-18998.

Zanne, A. E., et al. 2014. Three keys to the radiation of angiosperms into freezing environments. Nature 506:89-92.

\section{SUPPORTING INFORMATION}

Additional supporting information may be found in the online version of this article at http://onlinelibrary.wiley.com/ doi/10.1002/ecy.1771/suppinfo 